\title{
Anti-HIV-I drug toxicity and management strategies
}

This article was published in the following Dove Press journal:

Neurobehavioral HIV Medicine

2I April 20II

Number of times this article has been viewed

\section{Bechan Sharma \\ Department of Biochemistry, University of Allahabad, \\ Allahabad, India}

Correspondence: Bechan Sharma Department of Biochemistry, University of Allahabad, Allahabad-2I 1002, UP, India Tel +9l 94I 57I5639

$\mathrm{Fax}+9|532246| 157$

Email sharmabi@yahoo.com
Abstract: Antihuman immunodeficiency virus type 1 (anti-HIV-1) medications have helped millions of HIV-1-infected people lead longer and healthier lives. The goal of HIV-1 treatment is to reduce the number of virions in the body of infected individuals and to prevent rapid destruction of CD4+ T-lymphocyte cells, thus protecting the immune system. Most of the antiHIV-1 drugs in practice are designed using viral reverse transcriptase (HIV-1RT), protease, and integrase as targets. These drugs that inhibit the activities of HIV-1RT, viral protease, and integrase are therefore known as anti-HIV-1RT, antiprotease, and anti-integrase molecules, respectively. The US Food and Drug Administration has approved 22 anti-HIV-1/acquired immunodeficiency syndrome (AIDS) drugs for clinical use by HIV-1-infected individuals and AIDS patients. Among the drugs, most of the nucleoside analogs (excluding two isomers of 3TC, $(-) 3 \mathrm{TC}$ and $(+) 3 \mathrm{TC}$, which are shown to be less toxic in cell culture) exhibit clinical complications that pose a threat to chemotherapy. The toxicity of these molecules arises due to their negative impact on the activities of human mitochondrial chromosomal DNA polymerases $(\alpha, \delta, \beta$, and $\varepsilon)$ in general and DNA polymerase $\gamma$ in particular. Other anti-HIV-1 regimens are also reported to cause toxicity. The range of toxicity extends from mild to life-threatening levels. The prolonged use of zidovudine (3'-azido-3'-deoxythymidine [AZT] or Retrovir), which was first approved in 1987 as a nucleoside analog reverse transcriptase inhibitor, has been reported to cause severe hematologic toxicity, including severe anemia, granulocytopenia, and symptomatic myopathy. Many other drugs that are often used in combination with AZT have similar toxicities. The newer antiretrovirals (ARVs), such as $2^{\prime}, 3^{\prime}$-dideoxycytidine, $2^{\prime}, 3^{\prime}$-dideoxyinosine, and 2',3'-dideoxy-2',3'-didehydrothymidine, which exhibit analogous mechanisms of action and similar toxicities to AZT, have not been studied extensively. Acyclovir and gancyclovir can cause severe nausea and vomiting. Some of these ARVs when taken during pregnancy may generate teratogenic effects. Similarly, use of antiproteases in highly active ARV therapy causes hepatotoxicity, which poses a severe risk to the patients. In addition, application of fusion inhibitors and anti-integrases induces strong side effects in HIV-1-infected or AIDS patients. The present review illustrates a comprehensive analysis of the existing literature on the toxicity of anti-HIV-1/AIDS drugs, their mechanisms of action, and possible management strategies to combat this problem.

Keywords: HIV-1, AIDS, anti-HIV-1RT drugs, antiproteases, anti-integrases, fusion inhibitors, dosage, toxicity, management

\section{Introduction}

The treatment of human immunodeficiency virus type 1 (HIV-1)-infected individuals or those patients suffering from acquired immunodeficiency syndrome (AIDS) using currently available antiretroviral (ARV) drugs has significantly reduced mortality 
and morbidity rates. ${ }^{1-3}$ These patients are normally advised to continue taking medication for longer durations to subside the viral load and to improve the blood count of CD4+ T-lymphocyte cells. With long-term application, these regimens lead to the onset of marked side effects by developing adverse reactions, resulting in many metabolic disorders in the bodies of such patients. ${ }^{4}$ This phenomenon, in turn, exerts a negative impact on adherence, ${ }^{5}$ which has been considered one of the major causes of the emergence of drug-resistant variants of the virions causing AIDS. It is known that HIV-1 selects some drug-resistant mutants due to anti-HIV-1 drug pressure, ${ }^{6,7}$ and discontinuation of the ARV treatment due to the side effects of anti-HIV-1 chemotherapeutics further aggravates the situation. These limitations prompt the need to investigate some new, safer anti-HIV-1 molecules that are cost effective ${ }^{8}$ and with few or no toxic effects in patients.

After prolonged application, the different anti-HIV-1 drugs have been reported to induce varying forms of toxicity, such as peripheral neuropathy, myopathy, and pancreatitis. These toxic symptoms have been reported to emerge due to treatment of the patients with some of the nucleoside analogs such as $3^{\prime}$-azido- $3^{\prime}$-deoxythymidine (AZT) $,{ }^{9} 2^{\prime}, 3^{\prime}$-dideoxyinosine (ddI), ${ }^{10} 2^{\prime}, 3^{\prime}$-dideoxycytidine $(\mathrm{ddC}),{ }^{11,12}$ and $2^{\prime}, 3^{\prime}$-didehydro- $3^{\prime}$-deoxythymidine $(\mathrm{d} 4 \mathrm{~T}) .{ }^{13}$ However, the intensity of symptoms and severity of toxicity vary with each nucleoside analog, eg, AZT, ddI, and ddC, exert cytotoxic effects on human muscle cells, and trigger functional alterations in mitochondria. ${ }^{14}$ In addition, AZT has also been reported to cause myopathy in HIV-1-infected individuals. ${ }^{15}$

These nucleoside analogs may possess target specificity in their actions. They may select a specific cell, tissue, or organ as a target for their actions. ${ }^{14,15}$ However, these molecules may have differences in absorption, metabolism, distribution, excretion, and secretion profiles that may significantly influence their cellular bioavailability as well as activation and deactivation processes. All of these contribute to the development of any clinical toxicity in an HIV-1-infected individual. The development of symptoms of any side effect appears to be the outcome of the net effect of all these associated factors. ${ }^{14,16}$

The information available on various side effects arising from anti-HIV-1 drug usage for a prolonged time is scattered and limited. This review article is an endeavor to present an updated account of existing reports that are available on the toxicity of anti-HIV-1 regimens for HIV-1-infected or AIDS patients. This information will be highly useful to the wider audience, including academics, researchers, clinical pharmacologists, and physicians.

\section{The anti-HIV-I drugs}

The development of novel compounds that can effectively inhibit both wild-type and the most common resistant strains of HIV-1 is the primary focus in HIV disease management. Combination therapy, comprising at least three classes of drugs, has become the standard of care for AIDS- or HIV-1infected individuals. The drug cocktail can comprise all three classes of HIV-1 inhibitors, nucleoside reverse transcriptase inhibitors (NRTIs), non-nucleoside reverse transcriptase inhibitors (NNRTIs), and protease inhibitors (PIs). Due to their competitive mode of inhibition and requirement for metabolic activation, almost all NRTI drugs lack the virological potency of NNRTI or PI drugs. However, data from clinical trials indicate that sustained viral suppression cannot be achieved with NRTIs, NNRTIs, or PIs alone. Therefore, the NRTIs will remain essential components of highly active antiretroviral therapy (HAART) for the foreseeable future, because they enhance the virucidal potency of the regimens, because they do not bind excessively to protein, and because most regimens are small pills/tablets given once a day. ${ }^{16}$

It has become apparent in recent years that the prolonged use of certain NRTIs exhibits adverse events as a class, limiting the length of time for which they can be used safely. Of major clinical concern is their association with the potentially fatal lactic acidemia and hepatic steatosis. These class events, as well as individual drug effects such as peripheral neuropathy, are linked to delayed mitochondrial destruction. In addition to toxicity, the development of resistance-conferring mutations against exposure to nucleoside analogs currently in use influences long-term therapeutic benefits. Of critical importance for the evaluation of new NRTIs are recent studies showing that the efficiency of discrimination or excision by pyrophosphorolysis in the presence of nucleotides of a given NRTI is a key determinant in the emergence of resistance pathways. ${ }^{16}$

\section{Nucleoside reverse transcriptase inhibitors and their toxicity}

The NRTI drugs that are incorporated during synthesis of proviral cDNA inhibit the activity of viral RNA-dependent DNA polymerase (reverse transcriptase). Because they are dideoxy in nature (devoid of the presence of hydroxyl group at $2^{\prime}$ and $3^{\prime}$ positions in ribose sugar), the growing chain of cDNA during synthesis is therefore terminated, and hence these drugs are also called chain-terminator drugs. 
Examples of these drugs are i) zidovudine (3'-azido-3'deoxythymidine [AZT], Retrovir), which was first approved in 1987; ii) didanosine (ddI, Videx); iii) zalcitabine (ddC, Hivid); iv) stavudine (d4T, Zerit); vi) lamivudine (3TC, Epivir); and vii) tenofovir (Viread). The NRTIs approved by the US Food and Drug Administration (FDA) are Combivir, Emtriva, Epivir, Epzicom, Retrovir, Trizivir, Truvada, Videx, Viread, Zerit, and Ziagen. The first-generation NRTIs/ nucleotide reverse transcriptase inhibitors (NtRTIs) with related details are shown in Table 1. These compounds are also given in different possible combinations depending on the need of the HIV-1-infected or AIDS patients. Table 2 illustrates such combinations of the NRTIs/NtRTIs being prescribed to the HIV-1-infected or AIDS patients.

In prolonged ARV therapy with NRTIs, these compounds are reported to induce side effects in HIV-1-infected individuals. ${ }^{17}$ Some of these adverse effects arising due to application of NRTIs include nausea, intolerance, headaches, lactic acidosis, gastrointestinal ailments, hepatic steatosis (fatty liver), lipodystrophy, and pancreatitis (Table 3). Severe cases of lactic acidosis have been reported to be fatal. ${ }^{18}$ The toxic effects of most of the NRTIs are found to be mediated by mitochondrial damage. The mitochondrial damage by NRTIs includes not only perturbations in the structure of mitochondria but also depletion in mitochondria, ${ }^{17,19}$ which may lead to the onset of diseases associated with many vital organs of the body, such as the liver, pancreas, heart, muscles, kidneys, and nerves.

NRTIs may also cause hyperlactatemia by disrupting the function of the mitochondria. High levels of lactate in the blood, referred to as hyperlactatemia, occur either when too much lactate is made or when the liver is not working properly and is therefore unable to break it down. This is due to mitochondrial toxicity. When the mitochondria do not work efficiently, excess lactate is produced. Hence, NRTIs force the liver to become fatty, which is a condition called hepatic steatosis. A fatty liver does not work well and cannot break down lactate efficiently. Severe hyperlactatemia leads to lactic acidosis. Lactic acidosis is a serious but very rare complication of treatment with NRTIs. Although all NRTIs are associated with hyperlactatemia and lactic acidosis, people taking Zerit (stavudine) and Videx (didanosine) seem to be at greater risk than people taking other NRTIs.

NRTIs have also been reported to cause a reduction in the number of red blood cells (anemia), blood platelet count (thrombocytopenia), and neutrophils (neutropenia). It has been observed that each member of the NRTIs differs in their influence on mitochondria and hence the intensity of side effects. ${ }^{14,17,19}$ For example, only moderate mitochondrial damage is caused by tenofovir and emtricitabine as compared with other members of NRTIs. ${ }^{14,20,21}$ The NRTI-induced mitochondrial toxicity (or mitochondrial dysfunction) arises primarily due to damage of mitochondrial DNA, and it mostly takes place in the hepatic tissues and the skeletal muscles. The depletion of mitochondrial DNA appears to be due to incorporation of triphosphates of NRTI by DNA polymerase into the growing chain of DNA during its replication. ${ }^{17,19,22-24}$ The extent of damage to the mitochondrial DNA depends on the incorporation efficiency of NRTIs by mitochondrial DNA polymerase..$^{23,17}$ The dosage and side effects of NRTIs are summarized in Table 3.

\section{Mechanism of toxicity induced by nucleoside analogs}

The most acceptable mechanism for the toxicity of the nucleoside analogs is associated with the inhibition of the host cell DNA replication and repair activities. The enzymes responsible for the replication of mitochondrial chromosomal DNA (such as DNA polymerases $\alpha, \delta, \varepsilon$, and $\gamma$ ) as well as DNA repair (such as DNA polymerase $\beta$ ) ${ }^{25-27}$ are recognized as specific targets for the action of nucleoside analogs. ${ }^{14}$ The toxicity induced by AZT into the proliferating tissues, such as bone marrow cells, has been reported due to the inhibition of one or more of these DNA polymerases from mitochondria. ${ }^{28}$

Table I Nucleoside/nucleotide reverse transcriptase inhibitors with their details

\begin{tabular}{|c|c|c|c|c|}
\hline Abbreviation & Generic name & Brand name & Food restrictions and notes & $\begin{array}{l}\text { Date of US food and drug } \\
\text { administration approval }\end{array}$ \\
\hline 3TC & Lamivudine & Epivir & Take with or without food & November 17, 1995 \\
\hline$A B C$ & Abacavir & Ziagen & Take with or without food & December I7, 1998 \\
\hline AZT or ZDV & Zidovudine & Retrovir & Take with or without food & March 19, 1987 \\
\hline $\mathrm{d} 4 \mathrm{~T}$ & Stavudine & Zerit & Take with or without food & June 24,1994 \\
\hline ddl & Didanosine & Videx EC & $\begin{array}{l}\text { Take on an empty stomach } \\
30 \text { min before, or } 2 \mathrm{~h} \text { after, a meal }\end{array}$ & October 3I, 2000 \\
\hline FTC & Emtricitabine & Emtriva & Take with or without food & July 2, 2003 \\
\hline TDF & Tenofovir & Viread & Take with or without food & October 26, 200I \\
\hline
\end{tabular}

Source: http://www.avert.org/aids-drugs-table.htm. Reproduced with permission from US Food and Drug Administration. 
Table 2 Nucleoside/nucleotide reverse transcriptase inhibitors being prescribed as combined chemotherapeutic nucleotide reverse transcriptase inhibitors

\begin{tabular}{|c|c|c|c|}
\hline Combination & Brand name & Food restrictions and notes & $\begin{array}{l}\text { Date of US food and drug } \\
\text { administration approval }\end{array}$ \\
\hline $\mathrm{ABC}+3 \mathrm{TC}$ & $\begin{array}{l}\text { Epzicom (US), } \\
\text { Kivexa (Europe) }\end{array}$ & Take with or without food & August 2, 2004 \\
\hline$A B C+A Z T+3 T C$ & Trizivir & Take with or without food & November 14, 2000 \\
\hline $\mathrm{AZT}+3 \mathrm{TC}$ & Combivir & Take with or without food & September 27, I997 \\
\hline TDF + FTC & Truvada & Take with or without food & August 2, 2004 \\
\hline $\mathrm{d} 4 \mathrm{~T}+3 \mathrm{TC}$ & - & Take with or without food & Tentative only \\
\hline
\end{tabular}

Source: http://www.avert.org/aids-drugs-table.htm. Reproduced with permission from US Food and Drug Administration.

In contrast, the inhibition of the activity of chromosomal DNA polymerase $\gamma$ by the nucleoside analogs into the mitochondria from nonproliferating tissues is considered to be the main cause of toxicity. ${ }^{28-32}$ In support of this notion, the results reported by Medina et al ${ }^{33}$ revealed that the exposure of the cells to nucleoside analogs for longer treatment durations may cause a significant reduction in mitochondrial DNA synthesis, cell viability, and perturbations in the architecture of mitochondria. The results from the in vitro experiments conducted by Kukhanova et al ${ }^{34}$ have indicated that mitochondrial polymerase $\gamma$ is more sensitive to the nucleoside analogs than any of the other DNA polymerases, resulting in mitochondrial dysfunction. The mechanism of inhibition of human mitochondrial DNA polymerase $\gamma$ by the dideoxynucleoside analogs may involve in vivo phosphorylation to form the triphosphate in the cells and their subsequent incorporation into the DNA primer strand, resulting in chain termination. ${ }^{14}$ It is known that polymerase $\gamma$ consists of $3^{\prime}-5^{\prime}$-exonuclease activity that is responsible for correcting the newly synthesized DNA. ${ }^{35}$ The NRTIs possibly have the capability to inhibit the $3^{\prime}-5^{\prime}$-exonuclease function of this enzyme, resulting in mitochondrial toxicity by these compounds.

Another nucleotide analog that is widely used for the treatment of HIV infection is tenofovir. Tenofovir is a powerful antiviral drug treatment for hepatitis B and also an NtRTI, which blocks reverse transcriptase, an enzyme crucial to viral production in HIV-infected people. Tenofovir has been shown to exhibit relatively better efficacy and safety, but its prolonged application has been found to cause nephrotoxicity in patients..$^{36,37}$ Tenofovir was approved by the FDA on October 26, 2001 (Table 1).

Table 3 Nucleoside reverse transcriptase inhibitors, their dosages and side effects

\begin{tabular}{|c|c|c|}
\hline Drug & Dosage & Side effects/toxicity \\
\hline Retrovir/AZT & One 300 mg tablet daily & $\begin{array}{l}\text { Nausea, stomach discomfort, headache, insomnia, muscle wasting, } \\
\text { anemia, neutropenia (low white blood cell count). Medicine should be } \\
\text { taken with food to reduce stomach discomfort }\end{array}$ \\
\hline Epivir/3TC & One 300 mg tablet daily & $\begin{array}{l}\text { Nausea. Epivir is also taken for treatment of Hepatitis B virus but } \\
\text { with a different dosage }\end{array}$ \\
\hline Combivir/AZT + 3TC & One tablet (300 mg AZT + I50 mg 3TC) & $\begin{array}{l}\text { Nausea, vomiting, headache, loss of appetite, fatigue, stomach } \\
\text { discomfort, muscle wasting, anemia (low blood cell count), } \\
\text { neutropenia (low white blood cell count) }\end{array}$ \\
\hline Trizivir/AZT + 3TC + bacavir & $\begin{array}{l}\text { One tablet (300 mg AZT + I50 mg } \\
3 \mathrm{TC}+300 \mathrm{mg} \text { abacavir) twice daily }\end{array}$ & $\begin{array}{l}\text { Nausea, stomach discomfort, headache, insomnia, muscle wasting, } \\
\text { anemia, neutropenia (low white blood cell count) }\end{array}$ \\
\hline Ziagen/abacavir & One 300 mg tablet twice daily & $\begin{array}{l}\text { Nausea, vomiting, diarrhea, loss of appetite, insomnia, serious allergic } \\
\text { reactions in } 3 \%-5 \% \text { of patients with one death. The signs include fever, } \\
\text { malaise, nausea, diarrhea, abdominal pain, sore throat, cough, shortness } \\
\text { of breath, and rash }\end{array}$ \\
\hline Videx/ddl & & $\begin{array}{l}\text { Numbness, tingling, or pain in the hands or feet, nausea, vomiting, } \\
\text { diarrhea, headache, rash, pancreatitis (inflammation of pancreas) }\end{array}$ \\
\hline Zeritt/d4T & One 40 mg capsule, every $12 \mathrm{~h}$ & $\begin{array}{l}\text { Numbness, tingling, or pain in the hands or feet, nausea, diarrhea, } \\
\text { vomiting, headache, rash, pancreatitis, lactic acidosis }\end{array}$ \\
\hline $\mathrm{HIVid} / \mathrm{ddC}$ & $0.75 \mathrm{mg}$ tablet, every $8 \mathrm{~h}$ & $\begin{array}{l}\text { Numbness, tingling, or pain in the hands or feet, nausea, vomiting, } \\
\text { mouth ulcers. Drug is to be taken on an empty stomach }\end{array}$ \\
\hline Viread/tenofovir & One $300 \mathrm{mg}$ tablet once a day & Nausea, vomiting, diarrhea, intestinal gas \\
\hline Emtriva/emtricitabine & One 200 mg tablet daily & Headache, nausea, vomiting, diarrhea, rash \\
\hline
\end{tabular}

Source: http://www.medindia.net/patients/aids/treatment_nucleoside.htm, Reproduced with permission from medindia. Zalcitabine (ddC) was discontinued in 2006. 
Non-nucleoside analogs or non-nucleoside reverse transcriptase inhibitors and their toxicity

In contrast to NRTIs, NNRTIs are not incorporated into viral DNA, as they do not have structural similarities with those of regular deoxyribonucleoside triphosphate substrates; they inhibit HIV replication directly by binding noncompetitively to the viral reverse transcriptase. Some of the first-generation molecules are i) nevirapine (Viramune), ii) delavirdine (Rescriptor), and iii) efavirenz (Sustiva). Viramune, Rescriptor, and Sustiva are approved by the FDA. Their generic and brand names, food restrictions, and dates of FDA approval are shown in Table 4.

The dosages of different NNRTIs and their corresponding side effects are listed in Table 5. Etravirine (ETR) is the first representative of a new generation of NNRTIs and is indicated in patients with HIV infection and virological failure. The recommended dose is $200 \mathrm{mg}$ (two tablets) every 12 hours after a meal. ETR has good tolerability and the tablets can be dissolved in water, which can aid swallowing in some patients. This drug has a plasma half-life of 30-40 hours and consequently is a candidate for once-daily regimens. The most frequent adverse effect is rash (affecting $19 \%$ of patients), which is usually mild and does not lead to drug withdrawal. The studies, which compared ETR with placebo, with both groups receiving boosted darunavir and an optimized background regimen, did not demonstrate a higher incidence of liver toxicity, neuropsychiatric symptoms, gastrointestinal disturbances, or atherogenic dyslipidemia in patients receiving ETR. The safety profile of ETR suggests that it could be used as a substitute drug in patients with toxicity induced by first-generation NNRTIs or other ARV drugs. ${ }^{38}$ Most of the NNRTIs have been reported to cause allergic reactions, but these side effects are resolved after some time, as they are reversible in nature. The majority of the adverse events with NNRTIs occur within the first month and are predictable and manageable without therapy interruption. ${ }^{39}$ The most frequent adverse effect is the appearance of a rash on the body, which is observed with all FDA-approved NNRTIs. Rare cases of Stevens-Johnson syndromes (a serious systemic [bodywide] allergic reaction with a characteristic rash involving the skin and mucous membranes, including the buccal mucosa [inside of the mouth]) have also been reported. Elevations in the levels of parameters of liver function tests have been reported to be associated with application of these drugs. In addition, dysphoria, mood changes, depression, insomnia, somnolence, anxiety, vivid dreams, impaired concentration, and dizziness have been observed with treatment with efavirenz. ${ }^{40}$

\section{Mechanism of toxicity of NNRTIs}

The exact mechanism of toxicity of NNRTIs in patients under treatment is not clearly understood. However, NNRTIs such as nevirapine and efavirenz are known to cross the bloodbrain barrier even at very low concentration and reach the brains of HIV-1-infected and AIDS patients. These ARVs may then exert adverse effects to the central nervous systems (CNSs) of the patients and develop neurotoxic symptoms. ${ }^{41}$ The compounds have been observed to adversely influence anxiety-related behavior and cognitive performance in mice. ${ }^{42}$

\section{Viral protease inhibitors and toxicity of antiprotease drugs}

These drugs are specific for the HIV-1 protease and competitively inhibit enzyme activity, thereby preventing the maturation of virions capable of infecting other cells. Some of the antiprotease drugs are i) saquinavir (Invirase), which was first approved in 1995; ii) ritonavir (Norvir); iii) indinavir (Crixivan); iv) nelfinavir (Viracept); and v) amprenavir (Agenerase). PIs approved by the FDA are Agenerase, Aptivus, Crixivan, Fortovase, Invirase, Kaletra, Lexiva, Norvir, Reyataz, and Viracept. Treatment with indinavir has been found to be frequently associated with renal abnormalities and causes renal failure. ${ }^{43}$ Lipodystrophy and other fat distribution disorders have been reported in patients receiving PI therapy for HIV infection. ${ }^{44}$ PIs are reported to cause hepatotoxicity at any time from the start of medication. The generic and brand names, food restrictions, and FDA approval dates for these drugs are summarized in Table 6. The dosages and their side effects are listed in Table 7.

Table 4 Non-nucleoside reverse transcriptase inhibitors active against HIV-I and their details

\begin{tabular}{lllll}
\hline Abbreviation & Generic name & Brand name & Food restrictions and notes & $\begin{array}{c}\text { Date of US food and drug } \\
\text { administration approval }\end{array}$ \\
\hline DLV & Delavirdine & Rescriptor & Take with or without food & April 4, 1997 \\
EFV & Efavirenz & Sustiva (US), Stocrin (Europe) & Take on an empty stomach & September I7, I998 \\
ETR & Etravirine & Intelence & Take following a meal & January 18, 2008 \\
NVP & Nevirapine & Viramune & Take with or without food & June 2I, 1996 \\
\hline
\end{tabular}

Source: http://www.avert.org/aids-drugs-table.htm. Reproduced with permission from US Food and Drug Administration. 
Table 5 Non-nucleoside reverse transcriptase inhibitors, their dosages and side effects

\begin{tabular}{|c|c|c|}
\hline Drugs & Dosage & Side effects/toxicity \\
\hline $\begin{array}{l}\text { Nevirapine } \\
\text { (Viramun) }\end{array}$ & $\begin{array}{l}200,400, \text { or } \\
600 \mathrm{mg} \text { a day }\end{array}$ & $\begin{array}{l}\text { Headache, rash (usually in the first } 6 \\
\text { weeks of treatment), fatigue, liver } \\
\text { problems (usually in the first } 6 \text { weeks } \\
\text { of treatment), muscle pain, and nausea }\end{array}$ \\
\hline $\begin{array}{l}\text { Delavirdine } \\
\text { (Rescriptor) }\end{array}$ & $\begin{array}{l}200,400, \text { or } \\
600 \mathrm{mg} \text { a day }\end{array}$ & $\begin{array}{l}\text { Bronchitis, depression, diarrhea, } \\
\text { headache, nausea, redistribution of } \\
\text { body fat, sleeplessness, stomach pain }\end{array}$ \\
\hline $\begin{array}{l}\text { Efavirenz } \\
\text { (Sustiva) }\end{array}$ & $\begin{array}{l}600 \mathrm{mg} \text { taken } \\
\text { once daily }\end{array}$ & $\begin{array}{l}\text { Dizziness, anxiety, sleeplessness, } \\
\text { altered mental state, headache, sleep } \\
\text { disturbances, diarrhea, nausea, } \\
\text { vomiting, rash, and psychological } \\
\text { effects. These are most commonly } \\
\text { experienced during the first } 4 \text { weeks } \\
\text { of treatment and include feeling } \\
\text { "out of sorts", confusion, abnormal } \\
\text { dreams, disturbance in attention, and } \\
\text { depression. In most cases, these side } \\
\text { effects go away by themselves and it is } \\
\text { not necessary to stop taking efavirenz }\end{array}$ \\
\hline
\end{tabular}

\section{Fusion inhibitors}

Some peptide-based drugs have been investigated to act as fusion inhibitors. The action of these fusion inhibitors involves intervention in an essential step of viral entry, such as the formation of a transient structural intermediate during the HIV fusion process. These molecules act on the transmembrane glycoprotein gp41 of HIV. It is located on the surface of the virus and undergoes a conformational change after the docking of HIV-1 with viral gp120, another glycoprotein that is present on the surface of HIV-1. The conformational change in gp41 leads to the fusion of virus with the host cell membrane and the injection of viral genetic material inside the host cell. Direct binding to gp41 with fusion inhibitors such as enfuvirtide (Fuzeon, formerly T-20, molecular weight [MW] 4491.92) and its congener T-1249 ${ }^{16,45}$ strongly terminates the fusion process. The chemical constitution of T-20 indicates that it is a small polypeptide chain of 36 amino acid residues (MW 4491.92) with acylated tyrosine at the C-terminal and phenylalanine at the N-terminal. Its composition is Ac-YTS LIHSLIEESQNQQEKNEQELLELDKWASLWNWF-NH ${ }_{2}$. Some details about the fusion or entry inhibitors preventing HIV entry into cells are shown in Table 8, and their dosages and side effects are depicted in Table 9.

\section{Integrase inhibitors}

The viral integrase is responsible for catalyzing the process of integration of proviral cDNA randomly into the host genome. ${ }^{46}$ This enzyme has been targeted to develop an agent to block the integration reaction and hence to stop the replication of AIDS-causing virions inside the host cell. Integrase inhibitors that are active against HIV-1 and related details are shown in Table 10. Their dosages and side effects are shown in Table 11. A quantitative estimate of episodes of clinical toxicity requiring single ARV drug substitutions among ART-naïve adult patients in Uganda from May 2003 to December 2004 in a home-based AIDS care program is shown in Table $12 .{ }^{47,48}$

\section{Toxicity induced by anti-HIV-I drugs}

All FDA-approved NRTIs, NNRTIs, and PIs are associated with hepatotoxicity. NRTIs, especially Zerit (stavudine), Videx (didanosine), and Retrovir (zidovudine), are associated

Table 6 Protease inhibitors active against HIV-I and their details

\begin{tabular}{|c|c|c|c|c|}
\hline Abbreviation & Generic name & Brand name & Food restrictions and notes & $\begin{array}{l}\text { Date of US food and drug } \\
\text { administration approval }\end{array}$ \\
\hline APV & Amprenavir & Agenerase & Take with or without food; avoid high-fat meals & April 15, 1999 \\
\hline FOS-APV & Fosamprenavir & $\begin{array}{l}\text { Lexiva (US), } \\
\text { Telzir (Europe) }\end{array}$ & Take with or without food & October 20, 2003 \\
\hline ATV & Atazanavir & Reyataz & Take with food & June 20, 2003 \\
\hline DRV & Darunavir & Prezista & Take with food & June 23, 2006 \\
\hline IDV & Indinavir & Crixivan & $\begin{array}{l}\text { Take on an empty stomach I h before, or } \\
2 \mathrm{~h} \text { after, a meal. Avoid taking within I h } \\
\text { of taking didanosine ( } \mathrm{ddl} \text { or Videx) }\end{array}$ & March 13, 1996 \\
\hline LPV/RTV & $\begin{array}{l}\text { Lopinavir }+ \\
\text { Ritonavir }\end{array}$ & $\begin{array}{l}\text { Kaletra, Aluvia } \\
\text { (developing world) }\end{array}$ & $\begin{array}{l}\text { Some formulations should be taken } \\
\text { with food }\end{array}$ & September I5, 2000 \\
\hline NFV & Nelfinavir & Viracept & Take with food & March 14, 1997 \\
\hline RTV & Ritonavir & Norvir & Take with food if possible & March I, 1996 \\
\hline SQV & Saquinavir & $\begin{array}{l}\text { Invirase } \\
\text { (hard gel capsule) }\end{array}$ & Take within $2 \mathrm{~h}$ of food & December 6, 1995 \\
\hline TPV & Tipranavir & Aptivus & Take with or without food & June 22, 2005 \\
\hline
\end{tabular}

Source: http://www.avert.org/aids-drugs-table.htm. Reproduced with permission from US Food and Drug Administration. 
Table 7 Protease inhibitors, and their dosages and side effects

\begin{tabular}{|c|c|c|}
\hline Drugs & Dosage & Side effects/toxicity \\
\hline Atazanavir (Reyataz) & One $300 \mathrm{mg} \mathrm{PI}+$ one $100 \mathrm{mg}$ ritonavir once a day & $\begin{array}{l}\text { Common side effects: nondangerous yellowing } \\
\text { of the skin caused by increased levels of bilirubin, } \\
\text { peripheral neuropathy, headache, insomnia, } \\
\text { vomiting, diarrhea, abdominal pain, nausea, } \\
\text { indigestion, rash, tiredness. Rare side effects: } \\
\text { abnormal liver function, kidney stones and } \\
\text { pancreatitis }\end{array}$ \\
\hline Darunavir (Prezista) & $\begin{array}{l}\text { One } 600 \mathrm{mg} \mathrm{PI}+\text { one } 100 \mathrm{mg} \text { ritonavir capsule } \\
\text { twice a day. }\end{array}$ & Diarrhea, nausea, rash, and headache \\
\hline Fosamprenavir (Telzir) & $\begin{array}{l}\text { One } 700 \mathrm{mg} \mathrm{PI}+\text { one } 100 \mathrm{mg} \text { capsule of ritonavir } \\
\text { twice daily }\end{array}$ & $\begin{array}{l}\text { Diarrhea, increased blood fats, nausea, vomiting, } \\
\text { pain in the stomach, rash, headache, feeling dizzy, } \\
\text { tiredness, changes in liver and pancreas function }\end{array}$ \\
\hline Indinavir (Crixivan) & 800 mg PI (two 400 mg capsules) every 8 h & $\begin{array}{l}\text { Headache, dizziness, nausea, vomiting, diarrhea, } \\
\text { rash, kidney stones, fatigue, strange tastes in } \\
\text { the mouth, abdominal pain, sleep disturbance, } \\
\text { flatulence, dry mouth, acid regurgitation, ingrowing } \\
\text { toenails, dry skin and muscle pain }\end{array}$ \\
\hline Lopinavir/ritonavir (Kaletra) & $\begin{array}{l}400 \mathrm{mg} \text { lopinavir + } 100 \mathrm{mg} \text { ritonavir twice a day } \\
\text { (200 mg lopinavir and } 50 \mathrm{mg} \text { ritonavir each). } \\
\text { Four tablets once a day for patients starting } \\
\text { treatment for the first time }\end{array}$ & $\begin{array}{l}\text { Common side effects: diarrhea, insomnia, } \\
\text { headache, nausea, vomiting, abdominal pain, } \\
\text { abnormal stools, indigestion, flatulence, rash, } \\
\text { feeling weak, and changes in blood fats and sugars. } \\
\text { Rare side effects: abnormal kidney or liver function }\end{array}$ \\
\hline Nelfinavir (Viracept) & $\begin{array}{l}\text { Five } 250 \mathrm{mg} \text { tablets twice a day, or three } 250 \mathrm{mg} \\
\text { tablets three times a day }\end{array}$ & $\begin{array}{l}\text { Common side effects: diarrhea, nausea, flatulence, } \\
\text { rash, and metabolic abnormalities. Rare side } \\
\text { effects: jaundice and diabetes }\end{array}$ \\
\hline Ritonavir (Norvir) & $\begin{array}{l}100 \mathrm{mg} \text { or } 200 \mathrm{mg} \text { once or twice daily. } \\
\text { Ritonavir/atazanavir 100/300 mg once daily; } \\
\text { ritonavir/fosamprenavir } 100 / 700 \mathrm{mg} \text { twice daily; } \\
\text { ritonavir/darunavir } 100 \mathrm{mg} / 600 \mathrm{mg} \text { twice daily; } \\
\text { ritonavir/lopinavir } 100 \mathrm{mg} / 400 \mathrm{mg} \text { twice daily; } \\
\text { ritonavir/saquinavir } 100 \mathrm{mg} / 1000 \mathrm{mg} \text { twice daily; } \\
\text { ritonavir/tipranavir } 200 \mathrm{mg} / 500 \mathrm{mg} \text { twice a day }\end{array}$ & $\begin{array}{l}\text { Common side effects: diarrhea, stomach pain, } \\
\text { nausea, vomiting, weakness, taste abnormalities, } \\
\text { loss of appetite, numbness around the mouth, } \\
\text { metabolic abnormalities. Resistance to ritonavir: } \\
\text { causes resistance to indinavir and is likely to mean } \\
\text { some resistance to nelfinavir, saquinavir, and } \\
\text { fosamprenavir }\end{array}$ \\
\hline Saquinavir (Invirase) & $\begin{array}{l}\text { Two } 500 \mathrm{mg} \text { tablets }+ \text { one } 100 \mathrm{mg} \text { capsule of } \\
\text { ritonavir twice a day }\end{array}$ & $\begin{array}{l}\text { Common side effects: fatigue, anemia, nausea, } \\
\text { vomiting, and metabolic disorders. Rare side } \\
\text { effects: diabetes and Stevens-Johnson syndrome }\end{array}$ \\
\hline Tipranavir (Aptivus) & $\begin{array}{l}\text { Two } 250 \mathrm{mg} \text { capsules }+200 \mathrm{mg} \\
\text { (two } 100 \mathrm{mg} \text { capsules)ritonavir, twice a day }\end{array}$ & $\begin{array}{l}\text { Common side effects: diarrhea, nausea, vomiting, } \\
\text { abdominal pain, flatulence, tiredness, headache, } \\
\text { increased blood fats, liver abnormalities, and rash. } \\
\text { Rare side effects: diabetes and kidney problems }\end{array}$ \\
\hline
\end{tabular}

Data from: http://www.aidsmap.com/Integrase-inhibitors/page/l060I60/ @ 201I.

with lactic acidosis and hepatic steatosis. NNRTIs, especially Viramune (nevirapine), are associated with hepatitis and hepatic necrosis. Viramune-associated hepatotoxicity usually occurs within the first 12 weeks of taking the drug. Women appear to be at increased risk of liver damage. Some antiprotease molecules (PIs), especially full doses of Norvir (ritonavir) and Norvir-boosted Aptivus, are also associated with hepatotoxicity. Unlike Viramune, PIs may cause hepatotoxicity at any time. Patients infected with both HIV and hepatic $\mathrm{C}$ virus may be at particular risk for developing hepatotoxicity while taking PIs. In addition to hepatotoxicity, the administration of an anti-HIV-1 regimen to AIDS patients may also lead to some other kinds of toxicity, such as i) hepatotoxicity, ii) hyperglycemia, iii) hyperlipidemia, iv) lactic acidosis, v) lipodystrophy, vi) osteonecrosis, vii) osteoporosis, viii) osteopenia, and ix) skin rash.

\section{Hepatotoxicity}

Hepatotoxicity is a general term for liver damage. Certain medications, including those used to treat HIV infection, may cause hepatotoxicity. Hepatotoxicity has been reported to develop in HIV-infected people taking anti-HIV medications from three classes: NRTIs, NNRTIs, and PIs. There are several specific conditions that all fall within the general category of hepatotoxicity, which include i) hepatitis: inflammation of the liver, ii) hepatic necrosis: death of liver cells, and 
Table 8 Some details about the fusion or entry inhibitors preventing HIV entry into cells

\begin{tabular}{lllll}
\hline Abbreviation & Generic name & Brand name & Food restrictions and notes & $\begin{array}{l}\text { Date of US food and drug } \\
\text { administration approval }\end{array}$ \\
\hline T-20 & Enfuvirtide & Fuzeon & $\begin{array}{l}\text { Must be prepared from a powder and } \\
\text { injected into thigh, arm or abdomen }\end{array}$ & March 13, 2003 \\
MVC & Maraviroc & Celsentri (Europe) & Take with or without food & September I8, 2007 \\
\hline
\end{tabular}

Source: http://www.avert.org/aids-drugs-table.htm. Reproduced with permission from US food and drug administration.

iii) hepatic steatosis: too much fat in the liver, which may be associated with a life-threatening condition called lactic acidosis. The hepatotoxicity may be characterized by an increase in liver enzyme levels in the blood as the first sign of liver damage. Liver function tests may include tests to determine the levels of certain marker enzymes, such as alanine aminotransferase (ALT), aspartate aminotransferase (AST), and gamma-glutamyltransferase ( $\gamma \mathrm{GT})$. The intensity of signs and symptoms of hepatotoxicity greatly depend on the extent of damage caused to the liver. The general symptoms of liver damage include i) nausea, ii) vomiting, iii) abdominal pain, iv) loss of appetite, v) diarrhea, vi) feeling tired or weak, vii) jaundice (yellowing of the skin and eyes), and viii) hepatomegaly (liver enlargement). There are many other risk factors that may enhance hepatotoxicity in AIDS patients, such as infection with hepatitis B or C virus or high levels of certain liver enzymes prior to starting anti-HIV medications, or using alcohol or other medications that damage the liver. ${ }^{49,50}$

\section{Hyperglycemia}

Hyperglycemia is a disease condition in which the blood of a person contains a higher level of glucose than is normal. Generally, it happens shortly after having a meal. In healthy conditions, the blood glucose level sometimes returns to normal as the cells remove glucose from the blood by uptake in response to insulin. If the pancreas is damaged and it does not make enough insulin, glucose cannot enter the cells and remains in the blood. Blood glucose levels can also get too high if cells are unable to respond to insulin properly (insulin resistance). In the absence of an adequate amount of glucose, the cells of the body fail to generate sufficient energy to carry out its proper function. Hyperglycemia is caused by insulin resistance, as in type 2 diabetes. The mechanism is probably a treatment-related impairment of glucose transport and/or influence on intracellular phosphorylation of glucose. ${ }^{51}$ Hyperglycemia often develops in the patients receiving treatment with PIs, especially indinavir. This symptom is seen less frequently with NRTIs. ${ }^{52,53}$ The common symptoms of hyperglycemia include increased urination, excessive thirst or hunger, and unexplained weight loss. PI treatment of HIV-1 or hepatitis $\mathrm{C}$ virus-infected patients with HIV increases the risk of hyperglycemia and diabetes. The quantum of risk of onset of hyperglycemia is about the same with all PIs. However, certain factors, such as an increase in age and body weight and a prior history of diabetes in the family, may aggravate the risk of development of hyperglycemia.

\section{Hyperlipidemia}

Hyperlipidemia is characterized by an increase in concentration of fat, such as cholesterol and triglycerides, in the blood, which may cause heart disease and pancreatitis. Some of the

Table 9 Fusion and entry inhibitors preventing HIV entry into cells, their dosages and side effects

\begin{tabular}{|c|c|c|}
\hline Drug & Dosage & Side effects \\
\hline $\begin{array}{l}\text { T-20/enfuvirtide } \\
\text { (Fuzeon) }\end{array}$ & Subcutaneous injections ( $90 \mathrm{mg})$ twice a day & $\begin{array}{l}\text { Skin reactions at the site of injection, itching, swelling, } \\
\text { redness, pain or tenderness, hardened skin or bumps, } \\
\text { diarrhea, nausea, sinusitis, skin problems, influenza, ear } \\
\text { infection, decreased appetite, anorexia, anxiety, nightmares, } \\
\text { irritability, peripheral neuropathy, conjunctivitis, vertigo, } \\
\text { nasal congestion, pancreatitis, gastro-esophageal reflux } \\
\text { disease, muscle pain, flu-like illness, weakness }\end{array}$ \\
\hline $\begin{array}{l}\text { Maraviroc } \\
\text { (Celsentri) }\end{array}$ & $\begin{array}{l}300 \mathrm{mg} \text { (two I } 50 \mathrm{mg} \text { pills twice daily when combined with any } \\
\text { NRTIs, with raltegravir, tipranavir/ritonavir, efavirenz, or } \\
\text { nevirapine. One I50 mg pill twice daily when combined with } \\
\text { all other protease inhibitors. } 600 \mathrm{mg} \text { (four I } 50 \mathrm{mg} \text { pills twice } \\
\text { daily when combined with the NNRTI etravirine (Intelence) }\end{array}$ & $\begin{array}{l}\text { Common side effects: liver toxicities, abdominal pain, } \\
\text { cough, upper respiratory tract infections, sore muscles }\end{array}$ \\
\hline
\end{tabular}

Source: http://www.medindia.net/patients/aids/treatment_nucleoside.htm\#ixzz/9sPQUE7G. Reproduced with permission from medindia.

Abbreviations: NNRTI, non-nucleoside reverse transcriptase inhibitor; NRTI, nucleoside reverse transcriptase inhibitor. 
Table 10 Integrase inhibitor that is active against HIV-I and related details

\begin{tabular}{lllll}
\hline Abbreviation & Generic name & Brand name & Food restrictions and notes & $\begin{array}{l}\text { Date of US food and drug } \\
\text { administration approval }\end{array}$ \\
\hline RAL & Raltegravir & Isentress & Take with or without food & October 12, 2007 \\
\hline
\end{tabular}

Source: http://www.avert.org/aids-drugs-table.htm. Reproduced with permission from US food and drug administration.

PIs have been found to raise blood lipid (fat) levels in AIDS patients under treatment. PIs have also been shown to induce insulin resistance in addition to hyperlipidemia. ${ }^{54}$ One of the PIs, Norvir, has been found to be more likely to cause hyperlipidemia than other PIs. However, Sustiva, a non-PI, can also raise blood lipid levels. The factors associated with enhanced hyperlipidemia are alcohol intake, physical activity, and diet. In addition, hypothyroidism, diabetes, and genetic factors may also contribute to this process. Oral contraceptives (birth control pills) may also increase triglycerides and total cholesterol. The symptoms of hyperlipidemia are not a routine test for the levels of triglycerides, and total cholesterol tests are recommended quarterly. ${ }^{55,56}$

\section{Lactic acidosis}

Lactic acidosis is a rare but life-threatening clinical complication caused by the occurrence of a high concentration of lactate in the blood of patients, resulting in a significant lowering of blood $\mathrm{pH}$, which is harmful to the cells of the body. Lactic acid arises as a metabolic product from glycolysis in living cells. Lactic acid is quickly converted to lactate in the blood after losing a hydrogen atom. The hydrogen atom lost by lactic acid stays in the blood and decreases the blood's $\mathrm{pH}$ and makes it more acidic. People who are overweight are at increased risk of developing hepatic steatosis and lactic acidosis. Fatal lactic acidosis has been observed to occur in pregnant women taking a combination of Zerit and Videx. HIV-infected patients taking Rebetol (ribavirin) for hepatitis $\mathrm{C}$ virus infection may also be at increased risk for lactic acidosis. Mild hyperlactatemia does not show any symptoms. However, clinical symptoms due to severe hyperlactatemia and lactic acidosis include i) persistent nausea, vomiting, and abdominal pain; ii) unexplained tiredness; iii) shortness of breath; iv) rapid breathing; v) enlarged or tender liver; vi) cold or blue hands and feet; vii) abnormal heartbeat; and

Table II Integrase inhibitor that is active against HIV-I, its dosages and side effects

\begin{tabular}{lll}
\hline Drug & Dosage & Side effects \\
\hline Raltegravir & One $400 \mathrm{mg}$ & Common side effects: \\
(Isentress) & tablet twice a day & diarrhea, nausea, and headache \\
\hline
\end{tabular}

Data from: http://www.aidsmap.com/Integrase-inhibitors/page//060160/ ๑ 201 I. viii) weight loss. Liver function tests may reveal the levels of lactate, electrolyte, and blood $\mathrm{pH}$. In addition, physical examination may be performed to observe for an enlarged liver. A computed tomography (CT) scan or ultrasound of the liver may also be conducted in this context. Creatine phosphokinase, lactic dehydrogenase, lipase, amylase, $\gamma \mathrm{GT}$, and the anion gap may be increased; serum bicarbonate may be decreased. ${ }^{56-58}$

\section{Lipodystrophy}

Lipodystrophy means fat redistribution. It is due to disturbance in the production, utilization, and storage of fats in the body. There are mainly two kinds of lipodystrophy: i) fat wasting or lipoatrophy in which fat is lost from particular areas of the body, especially from the arms, legs, face,

Table 12 Quantitative estimates of episodes of clinical toxicity requiring single antiretroviral drug substitutions among antiretroviral therapy-naive adult patients in Uganda from May 2003 to December 2004 in a home-based AIDS care program ${ }^{47,48}$

\begin{tabular}{llll}
\hline Toxicity & Any (\%) & Severe (\%) & $\begin{array}{l}\text { Requiring drug } \\
\text { change (\%) }\end{array}$ \\
\hline Acute toxicity & 39.9 & 13.3 & 21.1 \\
Peripheral neuropathy & 36 & 9.3 & 17.2 \\
Rash & 5.7 & 2.4 & 3.8 \\
Clinical anemia & & 0.4 & 0.4 \\
Pancreatitis & & 0.3 & 0.1 \\
Acute hepatitis & & 0.1 & 0.1 \\
without rash & & & \\
Asthenia & 6.5 & 1.6 & \\
Vomiting & 2.9 & 0.2 & \\
Nausea & 2.7 & 0.2 & \\
Psychiatric disorder & 0.7 & 0.1 & \\
Pancreatitis & & 0.3 & \\
Lactic acidosis & & 0.1 & \\
Acute hepatitis & & 0.5 & \\
\hline
\end{tabular}

Notes: ${ }^{\mathrm{T}}$ The diseases were characterized based on the following specific symptoms. Peripheral neuropathy: presence of pain, tingling, numbness or weakness in the hands or feet, sensory loss, muscle weakness, or areflexia. Rash: characteristic skin lesions with or without mucous membrane ulcerations consistent with Stevens-Johnson syndrome. Anemia: presence of pallor and asthenia. Pancreatitis: presence of abdominal pain with nausea or vomiting. Acute hepatitis: presence of jaundice, liver enlargement, and gastrointestinal symptoms. Asthenia: presence of subjective weakness and fatigue. Psychiatric disorder: presence of abdominal pain, dreaming, impaired concentration, confusion, hallucinations, or mood swings. Lactic acidosis: presence of tachypnea or dyspnea with gastrointestinal or neurologic symptoms. Hypersensitivity: presence of fever and myalgia, arthralgia, or hepatitis with or without rash. Copyright (c) 2007, Wolters Kluwer Health. Reproduced with permission from Forna et al. ${ }^{47}$ 
and buttocks; and ii) fat accumulation or hyperadiposity, in which fat builds up in particular parts of the body, especially the belly, breasts, and back of the neck. Lipodystrophy may also lead to other metabolic disorders such as hyperlipidemia Lipodystrophy in combination with hyperlipidemia and insulin resistance is called lipodystrophy syndrome. Some studies have indicated that lipodystrophy is associated with the use of PIs. It is also linked to the use of NRTIs such as Zerit (stavudine, $\mathrm{d} 4 \mathrm{~T}$ ) and PIs at the same time. The extent of the syndrome largely depends on the length and severity of HIV infection, obesity, and age. However, other studies have shown that lipodystrophy also occurs in people who have never taken PIs. Lipodystrophy is detected by abdominal magnetic resonance imaging or CT scans, which can assess abdominal fat; however, there are currently no specific recommendations for routine assessment and monitoring of lipodystrophy. ${ }^{59-64}$

\section{Effect of anti-HIV-I compounds on the CNS and psychological status of HIV-I-infected and AIDS patients}

Despite the fact that combinatorial antiretroviral therapy has markedly reduced the morbidity and mortality of HIV-1 infection that is amenable to medical management, its long-term application has caused certain complications related to the CNS as well as to the psychological status of HIV-1-infected or AIDS patients. The anti-HIV-1 compounds exert toxic actions systemically and in the peripheral nervous system of the patients. However, not much is known about the toxicity of the compounds to neurons in the CNS. ${ }^{41}$ It has been reported that even low concentrations of ARVs that penetrate the blood-brain barrier may have detrimental effects on the CNS. The effects of 15 different ARV compounds and six combinations thereof on primary cultures of rat neurons have been studied to obtain a comparative assessment about the neurotoxicity of ARV compounds. From this study, it was concluded that these drugs produced neural toxicity at concentrations above $10 \mu \mathrm{g} / \mathrm{mL} .{ }^{41}$ In another study conducted in rats, nevirapine and efavirenz have been shown to cross the blood-brain barrier and cause significant inhibition in the activity of creatine kinase, which plays a major role in imparting cell energy homeostasis in the brain. ${ }^{65}$ This may also be associated with neurotoxicity of these ARVs. Further, the application of nevirapine and efavirenz has been found to impair the recognition memory, whereas treatment with only efavirenz impaired aversive memory in mice. ${ }^{42}$ Among the patients taking efavirenz, depression was found to occur more frequently than with any other ARV agent. Some of the adverse effects on the CNS include dizziness, insomnia, impaired concentration, somnolence, abnormal dreams, and hallucinations.

\section{Management of toxicity induced by anti-HIV-I drugs}

Toxicity due to long-term treatment with anti-HIV-1 drugs in general and HAART in particular is a common problem in HIV medication. Treating HIV-1-infected individuals is sometimes highly complicated, as many of them do not adhere to the treatment, switch over to a new regimen within a few weeks of starting therapy, or even refuse to begin HAART. ${ }^{48}$ Some of the options to overcome or reduce anti-HIV-1 drug-induced toxicity may include early diagnosis, monitoring of treatment by an HIV clinician at quarterly intervals, and standard evaluations of the patients' history, physical examinations, and measurement of vital signs and body weight. ${ }^{51}$

\section{Hepatotoxicity}

Patients should start taking anti-HIV medications only after getting a proper diagnosis for any liver disease. In case the patient is found to have any liver disease or any risk factors for developing hepatotoxicity, the physician may choose an HIV treatment regimen that significantly minimizes the risk of liver damage. In addition, a regular liver function test (biweekly or monthly) should be performed, particularly during the initial stage of intake of an anti-HIV regimen (http://aidsinfo.nih.gov). If the levels of liver enzymes such as ALT and AST are moderately elevated (about 3.5 times higher than normal), in the absence of clinical symptoms, treatment can be continued under close monitoring. If the levels of these enzymes are increased to more than 3.5 times the normal levels, additional diagnostic tests should be performed, including an abdominal ultrasound. ${ }^{51}$ Drugs such as nevirapine (NNRTI) and indinavir and ritonavir (PIs) may induce severe hepatotoxicity or even hepatic failure. Therefore, patients with pre-existing liver disease should receive these drugs only under strict monitoring. Different classes of anti-HIV-1 drugs induce hepatotoxicity at different time points. For example, treatment with nucleoside analogs for over 6 months may lead to hepatic steatosis, which is probably caused by mitochondrial toxicity. ${ }^{51,66,67}$

\section{Allergies}

The use of all the NNRTIs (especially nevirapine, delavirdine, and efavirenz), nucleoside analogs such as 
abacavir, and PIs such as amprenavir may induce allergic reactions or hypersensitivity manifested in the form of a rash on the body of patients about 100 times more frequently than in patients not on the drugs. The allergic reactions usually begin after 15-21 days of treatment. The symptoms include myalgia, fatigue, mucosal ulceration, rash, and fever. NNRTI-induced allergy is a reversible, systemic reaction and typically presents as an erythematous, maculopapular, pruritic, and confluent rash, distributed mainly over the trunk and arms. To overcome such allergic reactions, antihistamines may be used. Discontinuation of the treatment may be permitted if the mucous membranes are involved or upon the development of blisters, exfoliation, hepatic dysfunction (liver enzymes levels over five times the normal value), or fever $>39^{\circ} \mathrm{C}$. $^{51}$

\section{Hyperglycemia}

Hyperglycemia can be avoided by patients maintaining a healthy body weight or by taking proper medication if they are already suffering from diabetes. Frequent monitoring of blood glucose levels in the blood is essential to diagnose hyperglycemia, especially during the first year of treatment with a PI. ${ }^{56}$

\section{Hyperlipidemia}

To control hyperlipidemia, patients are advised to follow a low-fat diet and control body weight. In addition, regular aerobic exercise has been found to be helpful in regulating cholesterol levels. Factors such as smoking and alcohol intake are reported to enhance the concentration of cholesterol molecules in the blood. Therefore, patients are advised to not smoke or consume alcohol. Blood pressure needs to be maintained under supervision of a physician. Generally, this is achieved by medication using the statin group of compounds such as Lipitor (atorvastatin) and Pravachol (pravastatin) or the fibrate group of compounds such as Lopid (gemfibrozil) and Tricor (fenofibrate). ${ }^{56}$

\section{Lactic acidosis}

Lactate levels of $2-5 \mathrm{mmol} / \mathrm{dL}$ are considered to elicit symptoms in patients undergoing treatment with an antiHIV regimen. Levels greater than $5 \mathrm{mmol} / \mathrm{dL}$ are abnormal, and levels greater than $10 \mathrm{mmol} / \mathrm{dL}$ indicate a serious and possibly life-threatening situation. Lactic acidosis is treated first by discontinuing intake of any NRTIs on the advice of a physician. Some people with lactic acidosis need intravenous fluids and a machine to help them breathe. Some doctors recommend giving riboflavin (vitamin B2), thiamine (vitamin B1), coenzyme Q, L-carnitine, or vitamins C, E, and $\mathrm{K}$ to patients with lactic acidosis, but the effectiveness of these treatments is uncertain. During mild hyperlactatemia, normally, the HIV treatment regimen is not discontinued, as such patients have relatively lower risk for lactic acidosis. If the resistance profile allows, NRTI treatment may be modified, such as a switch from d4T/ddI to abacavir, zidovudine, or tenofovir. ${ }^{56,68}$

\section{Lipodystrophy}

There are no clearly effective treatments for lipodystrophy. However, people with lipodystrophy may benefit from changes to their HIV treatment regimens. If the patients are taking Zerit, switching to Ziagen (abacavir) on the advice of a physician may help reduce lipodystrophy. ${ }^{56}$ PIs may be replaced with NNRTIs, which do not appear to cause lipodystrophy. In addition, diet and exercise have also been reported to play a role in muscle building and reduction of fat. If a patient is insulin resistant and hyperglycemic, the drug glucophage (metformin) may help decrease abdominal fat. In cases of fat wasting, injections of human growth hormone may boost muscle size in the arms and legs. Injections of fat or synthetic fat substitutes like Sculptra can fill out sunken cheeks, as can cosmetic cheek implants as per FDA approval in August 2004 (http://aidsinfo.nih.gov).

\section{Gastrointestinal disorders}

In the early stages of chemotherapy with nucleoside analogs, NNRTIs, and PIs, there may be symptoms of gastrointestinal disorders, such as abdominal discomfort, loss of appetite, diarrhea, nausea, and vomiting. Heartburn, abdominal pain, meteorism, dehydration, malnutrition with weight loss, low plasma drug levels, and constipation may also develop. Diarrhea occurs frequently with zidovudine, didanosine, and all PIs (nelfinavir, saquinavir, and lopinavir), whereas nausea is commonly produced by zidovudine. ${ }^{51}$ In many cases, such disorders are resolved between 1 month and 6 weeks of treatment. To avoid these complications, the medication should not be taken on an empty stomach. Coffee, smoking, alcohol, aspirin, very spicy or fatty foods, and dairy products should be avoided. For symptomatic treatment, metoclopramide, dimenhydrinate, cimetidine, ranitidine, or ondansetron is normally prescribed. Antiemetic drugs can be taken 30-45 minutes before HAART regularly, but after a few weeks they can be gradually withdrawn. In cases of PIassociated diarrhea, oat bran tablets or psyllium may be useful. Nelfinavir-associated diarrhea is alleviated by calcium, taken as calcium carbonate, at a dosage of $500 \mathrm{mg}$ bid. To 
inhibit bowel movements arising due to PI usage, loperamide or opium tincture or pancrelipase, a synthetic pancreatic enzyme, may be taken on the advice of a physician. To avoid significant dehydration and loss of electrolytes, soft drinks, salty crackers, sport drinks, herbal teas, and electrolyte solutions may be useful..$^{51,66,67}$

\section{Disorders of the CNS}

It is reported that about $40 \%$ of patients treated with efavirenz develop toxicity related to the CNS during the first week of treatment. Dosing at bedtime seems to improve the tolerability of the neurotoxicity symptoms and can be recommended during the first weeks of therapy. The symptoms include dizziness, insomnia, nightmares, mood changes, depression, and depersonalization. ${ }^{51}$ Such complications may be averted by treating the patients with lorazepam. However, haloperidol can be given for panic attacks and nightmares. The patients should be informed about such symptoms, which are usually resolved after some time. The NNRTIs generally do not cause such toxic effects. ${ }^{66,68,69}$ Patients should be alerted to the potential for additive CNS effects when efavirenz is used concomitantly with alcohol or psychoactive drugs. Patients with CNS symptoms such as dizziness, impaired concentration, and/or drowsiness should avoid stressful tasks such as driving or operating machinery. In addition, some psychiatric symptoms can develop, such as severe depression, suicidal ideation/attempts, aggressive behavior, paranoid reactions, and manic reactions. Patients with a prior history of psychiatric disorders appear to be at greater risk for these psychiatric adverse experiences. Patients with serious psychiatric adverse experiences should seek immediate medical evaluation to assess the possibility that the symptoms may be related to the use of efavirenz and, if so, to determine whether the risks of continued therapy outweigh the benefits.

\section{Peripheral polyneuropathy}

Nucleoside analogs such as zalcitabine, didanosine, and stavudine have been found to induce peripheral polyneuropathy. The symptoms include distal symmetrical distribution, sensorimotor paralysis, paresthesia, and pain in the hands and feet. The risk factors for polyneuropathy include treatment with other neurotoxic drugs, vitamin B12 deficiency, alcohol abuse, and diabetes mellitus. These symptoms disappear within 2 months after withdrawal of the drug concerned. For the treatment of such toxicity, there is no specific therapy. Cold showers may relieve pain before going to bed. Tight shoes and long periods of standing or walking should be avoided. ${ }^{51}$

\section{Renal toxicity}

Treatment of HIV-1-infected patients with indinavir may lead to kidney damage due to the formation of indinavir crystals, which may be found in the urine of some patients, very rarely causing renal failure. ${ }^{70,71}$ Symptoms of pain in the back and lower abdominal regions may develop. Pain may even extend to the groin or testes. Such patients are advised to routinely take up physical examinations, ultrasound, and renal function tests. ${ }^{51}$ For acute therapy, physicians normally prescribe analgesia drugs such as metamizole or diclofenac in combination with spasmolytic drugs such as butylscopolamine. If this treatment fails, an intravenous or intramuscular dose of pethidine may be administered. Nonsteroidal anti-inflammatory drugs such as quinolones, ampicillin, foscarnet, aciclovir, sulfonamides (cotrimoxazole, sulfadiazine), and allopurinol can also cause nephrolithiasis. Therefore, the use of these drugs requires special care when given in combination with indinavir. ${ }^{51,72}$

\section{Conclusion}

HIV-1/AIDS patients are currently being treated with a single drug or different combinations of 22 ARV agents approved by the FDA for clinical use. These drugs have been developed to target viral enzymes such as HIV-1RT, protease, and integrase encoded by the pol gene of the virus. Several small molecules have also been developed against different stages of the viral life-cycle. Some of them have entered into various stages of basic and clinical development. Most of these drugs have been found to induce moderate to severe toxic effects after long-term use and therefore pose a challenge to chemotherapy. Because of the side effects, adherence to treatment has always been at stake, and discontinuation of the treatment in many cases further aggravates the drug resistance problem. Therefore, knowledge about the mechanisms of action of these drugs, their interactions with other concomitantly administered drugs, development of newer and safer ARVs, and effective management practices to combat drug-induced toxicity are urgently required for successful treatment of the disease.

\section{Disclosure}

The author reports no conflicts of interest in this work.

\section{References}

1. Palella FJ Jr, Delaney KM, Moorman AC, et al. Declining morbidity and mortality among patients with advanced human immunodeficiency virus infection. HIV Outpatient Study Investigators. $N$ Engl J Med. 1998;338:853-860.

2. Detels R, Tarwater P, Phair JP, et al. Effectiveness of potent antiretroviral therapies on the incidence of opportunistic infections before and after AIDS diagnosis. AIDS. 2001;15:347-355. 
3. Ives NJ, Gazzard BG, Easterbrook PJ. The changing pattern of AIDSdefining illnesses with the introduction of highly active antiretroviral therapy (HAART) in a London clinic. J Infect. 2001:42:134-139.

4. Stenzel MS, Carpenter CC. The management of the clinical complications of antiretroviral therapy. Infect Dis Clin North Am. 2000;14 851-178, vi.

5. Andrews L, Friedland G. Progress in HIV therapeutics and the challenges of adherence to antiretroviral therapy. Infect Dis Clin North Am. 2000;14:901-928.

6. Kartsonis NA, D'Aquila RT. Clinical monitoring of HIV-1 infection in the ERA of antiretroviral resistance testing. Infect Dis Clin North Am. 2000;14:879-899.

7. Richman DD. HIV chemotherapy. Nature. 2001;410:995-1001.

8. Keiser P, Nassar N, Kvanli MB, et al. Long-term impact of highly active antiretroviral therapy on HIV related health care costs. J Acquir Immune Defic Syndr. 2001;27:14-19.

9. Wildo MI, Langtry HD. Zidovudine: an update of its pharmacodynamic and pharmacokinetic properties, and therapeutic efficacy. Drugs. 1993;46:515-578.

10. Faulds D, Brogden RN. Didanosine: a review of its antiviral activity, pharmacokinetic properties and therapeutic potential in human immunodeficiency virus infection. Drugs. 1992;44:94-116.

11. Whittington R, Brogden RN. Zalcitabine: a review of its pharmacology and clinical potential in acquired immunodeficiency syndrome (AIDS) Drugs. 1992;44:656-683.

12. De-Clercq E. Anti-HIV drugs: 25 compounds approved within 25 years after the discovery of HIV. Int J Antimicrob Agents. 2009;33: 307-320.

13. Cihlar T, Ray AS. Nucleoside and nucleotide HIV reverse transcriptase inhibitors: 25 years after zidovudine. Antiviral Res. 2010;85: 39-58.

14. Feng JY, Johnson AA, Johnsoni KA, Anderson KS. Insights into the molecular mechanism of mitochondrial toxicity by AIDS drugs. J Biol Chem. 2001;276:23832-23837.

15. Benbrik E, Chariot $\mathrm{P}$, Bonavaud $\mathrm{S}$, et al. Cellular and mitochondrial toxicity of zidovudine (AZT), didanosine (ddI) and zalcitabine (ddC) on cultured human muscle cells. J Neurol Sci. 1997;149:19-25.

16. Warnke D, Barreto J, Temesgen Z. Antiretroviral drugs. J Clin Pharmacol. 2007;47:1570-1579.

17. Safadi YE, Vivet-Boudou V, Marquet R. HIV-1 reverse transcriptase inhibitors. Appl Microbiol Biotechnol. 2007;75:723-737.

18. Sundar K, Suarez M, Banogon PE, Shapiro JM. Zidovudineinduced fatal lactic acidosis and hepatic failure in patients with acquired immunodeficiency syndrome: report of two patients and review of the literature. Crit Care Med. 1997;25:1425-1430.

19. Kakuda TN. Pharmacology of nucleoside and nucleotide reverse transcriptase inhibitor-induced mitochondrial toxicity. Clin Ther. 2010; 22:2717-2747.

20. Birkus G, Hitchcock MJ, Cihlar T. Assessment of mitochondrial toxicity in human cells treated with tenofovir: comparison with other nucleoside reverse transcriptase inhibitors. Antimicrob Agents Chemother. 2002; 46:716-723.

21. Vidal F, Domingo JC, Guallar J, et al. In vitro cytotoxicity and mitochondrial toxicity of tenofovir alone and in combination with other antiretrovirals in human renal proximal tubule cells. Antimicrob Agents Chemother. 2006;50:3824-3832.

22. Johnson AA, Ray AS, Hanes J, et al. Toxicity of antiviral nucleoside analogs and the human mitochondrial DNA polymerase. J Biol Chem. 2001;276:40847-40857

23. Lee H, Hanes J, Johnson KA. Toxicity of nucleoside analogues used to treat AIDS and the selectivity of the mitochondrial DNA polymerase. Biochemistry. 2003;42:14711-14719.

24. Moyle $\mathrm{G}$. The emerging roles of non-nucleoside reverse transcriptase inhibitors in antiretroviral therapy. Drugs. 2001;61:19-26.

25. Frick LW, Nelson DJ, St. Clair MH, et al. Effects of $3^{\prime}$-zido-3'deoxythymidine on the deoxynucleotide triphosphate pools of cultured human cells. Biochem Biophys Res Commun. 1988;154:124-129.
26. Hall ET, Yan JP, Melancon P, Kuchta RD. 3-azido-3-deoxythymidine potentially inhibits protein glycosylation. J Biol Chem. 1994;269: 14355-14358.

27. Kewn S, Veal GJ, Hoggard PG, et al. Lamivudine (3TC) phosphorylation and drug interactions in vitro. Biochem Pharmacol. 1997;54: 589-595.

28. Parker WB, Cheng Y-C. Mitochondrial toxicity of antiviral nucleoside analogs. J Natl Inst Health Res. 1994;6:57-61.

29. Horn DM, Neeb LA, Colacino JM, Richardson FC. Fialuridine is phosphorylated and inhibits DNA synthesis in isolated rat hepatic mitochondria. Antiviral Res. 1997;34:71-74.

30. Colacino JM. Mechanisms for the anti-hepatitis B virus activity and mitochondrial toxicity of fialuridine (FIAU). Antiviral Res. 1996;29: 125-139.

31. Honkoop P, Scholte HR, de Man RA, Schalm SW. Mitochondrial injury. Lessons from the fialuridine trial. Drug Safety. 1997;17:1-7.

32. Barile M, Valenti D, Quagliariello E, Passarella S. Mitochondria as cell targets of AZT (zidovudine). Gen Pharmacol. 1998;31:531-538.

33. Medina DJ, Tsai CH, Hsiung GD, Cheng YC. Comparison of mitochondrial morphology, mitochondrial DNA content, and cell viability in cultured cells treated with three anti-human immunodeficiency virus dideoxynucleosides. Antimicrob Agents Chemother. 1994;38: 1824-1828.

34. Kukhanova M, Liu S-H, Mozzherin D, et al. J Biol Chem. 1995;270: 23055-23059.

35. Olson MW, Kaguni LS. 3'-5' exonuclease in Drosophila mitochondrial DNA polymerase: substrate specificity and functional coordination of nucleotide: polymerization and mispair hydrolysis. J Biol Chem. 1992; 267:23136-23142

36. Kearney BP, Yale K, Shah J, et al. Pharmacokinetics and dosing recommendations of tenofovir disoproxil fumarate in hepatic or renal impairment. Clin Pharmacokinet. 2006;45:1115-1124.

37. Rodríguez-Nóvoa S, Labarga P, D'avolio A, et al. Impairment in kidney tubular function in patients receiving tenofovir is associated with higher tenofovir plasma concentrations. AIDS. 2010;24: 1064-1066

38. Portilla J. Safety and tolerability of etravirine. Enferm Infecc Microbiol Clin. 2009;Suppl 2:21-26.

39. Moyle G. Mechanisms of HIV and nucleoside reverse transcriptase inhibitor injury to mitochondria. Antivir Ther. 2005;10(Suppl 2): M47-M52.

40. Weller IV, Williams IG. ABC of AIDS. Antiretroviral drugs. Brit Med J. 2001;322:1410-1412.

41. Liner J, Meeker RB, Robertson K. 17th CROI Conference on Retroviruses and Opportunistic Infections; February 16-19, 2010; San Francisco, CA, USA.

42. Romão PRT, Lemos JC, Moreira J, et al. Anti-HIV drugs nevirapine and efavirenz affect anxiety-related behavior and cognitive performance in mice. Neurotoxicity Res. 2009;19(1):73-80

43. Eira M, Araujo M, Seguro AC. Urinary NO3 excretion and renal failure in indinavir-treated patients. Brazilian J Med Biol Res. 2006;39: 1065-1070.

44. Milpied-Homsi B, Krempf M, Gueglio B, et al. Buffalo neck: an unintended secondary effect of treatment with anti-HIV protease inhibitors. Ann Dermatol Venereol. 1999;126:254-256.

45. Tandon VK, Chhor RB. Current status of anti-HIV agents. Curr Med Chem. 2005;4:3-28.

46. Levin A, Armon-Omer A, Rosenbluh J, et al. Inhibition of HIV-1 integrase nuclear import and replication by a peptide bearing integrase putative nuclear localization signal. Retrovirology. 2009;6: 112-117.

47. Forna F, Liechty CA, Solberg P, et al. Clinical toxicity of highly active antiretroviral therapy in a home-based AIDS care programme in rural Uganda. J Aquir Immune Defic Syndrome. 2007;44:456-462.

48. Rivero A, Mira JA, Pineda JA. Liver toxicity induced by non-nucleoside reversetranscriptase inhibitors. J Antimicrob Chemother. 2007;59: $342-346$. 
49. Ciccacci C, Borgiani P, Ceffa S, et al. Nevirapine-induced hepatotoxicity and pharmacogenetics: a retrospective study in a population from Mozambique. Pharmacogenomics. 2010;11:23-31.

50. Murakami T, Yamamoto N. Role of CXCR4 in HIV infection and its potential as a therapeutic target. Future Microbiol. 2010;5(7): 1025-1039.

51. Hoffmann C, Kamps BS. Management of side effects. HIV Medicine. Paris: Flying Publisher; 2003.

52. Hardy H, Esch LD, Morse GD. Glucose disorders associated with HIV and its drug therapy. Ann Pharmacother. 2001;35:343-351.

53. Modest GA, Fuller J. Abacavir and diabetes. N Engl J Med. 2001;344: 142-144.

54. Faria AMC, Weiner HL. Oral tolerance: mechanisms and therapeutic applications. Advances in Immunol. 1999;73:153-264.

55. Harrington M, Carpenter C. Hit HIV-1 hard, but only when necessary. Lancet. 2000;355:2147-2152.

56. Vidal F, Gutierrez F, Gutierrez M, et al. Pharmacogenetics of adverse effects due to antiretroviral drugs. AIDS Review. 2010;12:15-30.

57. Bleeker-Rovers CP, Kadir SW, van Leusen R, Richter C. Hepatic steatosis and lactic acidosis caused by stavudine in an HIV-infected patient. Neth J Med. 2000;57:190-193.

58. Lai H-Y, Chen J-H, Tsai P-P, et al. Hepatic steatosis and pancreatitis associated with the use of stavudine in a patient with HIV infection. Am J Roentgenology. 2004;183:1605-1607.

59. Villarroya F, Domingo P, Giralt M. Drug-induced lipotoxicity: lipodystrophy associated with HIV-1 infection and antiretroviral treatment. Biochim Biophys Acta. 2010;1801:392-399.

60. Barbaro G. Heart and HAART: two sides of the coin for HIV-associated cardiology issues. World J Cardiol. 2010;2:53-57.

61. Caron-Debarle M, Boccara M, Lagathu F, et al. Adipose tissue as a target of hiv-1 antiretroviral drugs. potential consequences on metabolic regulations. Curr Pharm Des. 2010;16:3352-3360.
62. Caron-Debarle M, Lagathu C, Boccara F, et al. HIV-associated lipodystrophy: from fat injury to premature aging. Trends $\mathrm{Mol} \mathrm{Med}$. 2010;16:218-229.

63. Vassimon HS, Deminice R, Machado AA, et al. The association of lipodystrophy and oxidative stress biomarkers in HIV-infected men. Curr HIV Res. 2010;8:364-369.

64. Potthoff A, Brockmeyer NH, Gelbrich G, et al. Lipodystrophy: a sign for metabolic syndrome in patients of the HIV-HEART study. $J$ Dtsch Dermatol Ges. 2010;8:92-98.

65. Streck EL, Scaini G, Rezin GT, et al. Effects of the HIV treatment drugs nevirapine and efavirenz on brain creatine kinase activity. Metabolic Brain Disease. 2008;23:485-492.

66. Highleyman L. Adverse effects associated with antiretroviral therapy. Bulletin of Experimental Treatments for AIDS. San Francisco: BETA Spring; 2000.

67. Carr A, Morey A, Mallon P, et al. Fatal portal hypertension, liver failure, and mitochondrial dysfunction after HIV-1 nucleoside analogue-induced hepatitis and lactic acidaemia. Lancet. 2001;357:1412-1414.

68. Bussmann H, Wester CW, Thomas A, et al. Response to zidovudine/ didanosine-containing combination antiretroviral therapy among HIV-1 subtype C-infected adults in Botswana: two-year outcomes from a randomized clinical trial. J Acquir Immune Defic Syndr. 2009;51:37-46.

69. Highleyman L. Managing nausea, vomiting, and diarrhea. BETA Spring. 2002;15:29-39.

70. Olyaei AJ, deMattos AM, Bennett WM. Renal toxicity of protease inhibitors. Curr Opin Nephrol Hypertens. 2000;9:473-476.

71. Kopp JB. Renal dysfunction in HIV-1-infected patients. Curr Infect Dis Rep. 2002;4:449-460.

72. Boubaker K, Sudre P, Bally F, et al. Changes in renal function associated with indinavir. AIDS. 1998;12:F249-F254
Neurobehavioral HIV Medicine

\section{Publish your work in this journal}

Neurobehavioral HIV Medicine is an international, peer-reviewed, open access journal focusing on advances in research in HIV/ AIDS, with specific reference to the neurological, psychiatric and behavioral consequences of the disease, concomitant infections and specific antiretroviral therapy. The manuscript

\section{Dovepress}

management system is completely online and includes a very quick and fair peer-review system, which is all easy to use. Visit http://www.dovepress.com/testimonials.php to read real quotes from published authors. 